Ciência e Natura, Santa Maria v.39 n.3, 2017, Set - Dez, p. 553 - 568

Revista do Centro de Ciências Naturais e Exatas - UFSM

ISSN impressa: 0100-8307 ISSN on-line: 2179-460X

\title{
CIÊNCIANATURA
}

\section{Modeling of plasma spray coating process using robust solutions based on new intelligence methods}

\author{
Mehdi Abedi-Varaki ${ }^{1}$, Shahram Mollaiy-Berneti ${ }^{1, *}$ \\ ${ }^{1)}$ Young Researchers and Elite Club, Bandar Abbas Branch, Islamic Azad University, Bandar Abbas, Iran \\ sh.m.berneti@gmail.com
}

\begin{abstract}
This study adopts two computational intelligence techniques namely least-squares support vector machine (LS-SVM) and group method of data handling (GMDH) type polynomial neural network to model the plasma spray coating process. The coating qualities were evaluated by determining its thickness, porosity and micro-hardness. Four parameters including primary gas flow rate, stand-off distance, powder flow rate and arc current that affecting the coating properties were chosen as input variables in model development. The performances of the developed models were evaluated by calculating the deviations between the predicted and the actual values based on the performance indices of mean absolute error (MAE), root mean square error (RMSE) and coefficient of determination $\left(R^{2}\right)$. The results demonstrate the high capability of the LS-SVM and GMDH-type polynomial neural network for prediction of thickness and micro-hardness values with lowest MAE, RMSE and highest $R^{2}$. Due to the high non-linearity behavior of porosity in coating process, the proposed methods are not able to model porosity very well.
\end{abstract}

Keywords: Plasma spray coating; coating properties; least-squares support vector machine; GMDH-type polynomial neural network 


\section{Introduction}

Thermal spray plasma is a technology that generally applied for thermal barrier coatings (TBCs) especially in gasturbine engines blades. Gas-turbine engines performance has a key role in industry, especially in transportation and defense sections which depends on high temperature TBCs. Protecting and insulating super-alloys used in gas-turbine is an important issue. Due to low thermal conductivity and high melting point of TBCs, surfaces of metallic in gas-turbine engines are coated with this technology (Evans et al., 2001), (Padture et al., 2002), (Levi, 2004), (Clarke and Levi, 2003), (Evans et al., 2008), (Vaßen et al., 2010), (Bathie), (Perepezko, 2009).

The plasma spray is a process of heat softened material spraying or molten material coating into an external surface. Contents of powders are injected with high temperature and high velocity. The heated materials impact on the substrate surface in which forming of coating rapidly cooled. The plasma spray process also called a cold process owing to substrate temperature can be kept low in this process and quickly cooled. As shown in Fig 1, the plasma spray gun consists of cathode and anode. Tungsten and copper are used as cathode and anode, respectively. Anode is shaped as a condensing nozzle. The plasma gas typically argon flows around the cathode and anode.

Application of Direct Current (DC) along radial direction between anode and cathode and consequent appearance of radial electric field cause the electrical arc discharge resulting in the formation of plasma. Ionization of gas and plasma formation, and the resistance heating from the arc discharge causes gas to reach high temperatures and ions dissociate from plasma (Abedi-Varaki and Davtalab, 2016; Abedi-Varaki et al., 2015). By producing the stabilized plasma, electrical arc discharge extends down the nozzle, instead of shorting out to the nearest edge of anode nozzle. This stretching is called thermal pinch effect. When gas turn around the surface of cooled water, anode nozzle being electrically non-conductive shrunken and the velocity and temperature of the plasma arc are increased (Raizer, 1987). Splats, pores and cracks may occur within TBCs in coating process that it can show drastic reduce thermal conductivity of coating process.

Since microstructures nonlinear elastic modulus, properties of coating process such as durability, hardness, porosity rate, thickness for desired quality of TBCs must be control and sustain. Plasma spray coating is complicating process and not yet fully understood. In such situations, development of models from the results of empirical data can be useful for prediction of desired output. Some studies on the plasma spray coating process for determining input-output relationship have been presented in recent years.

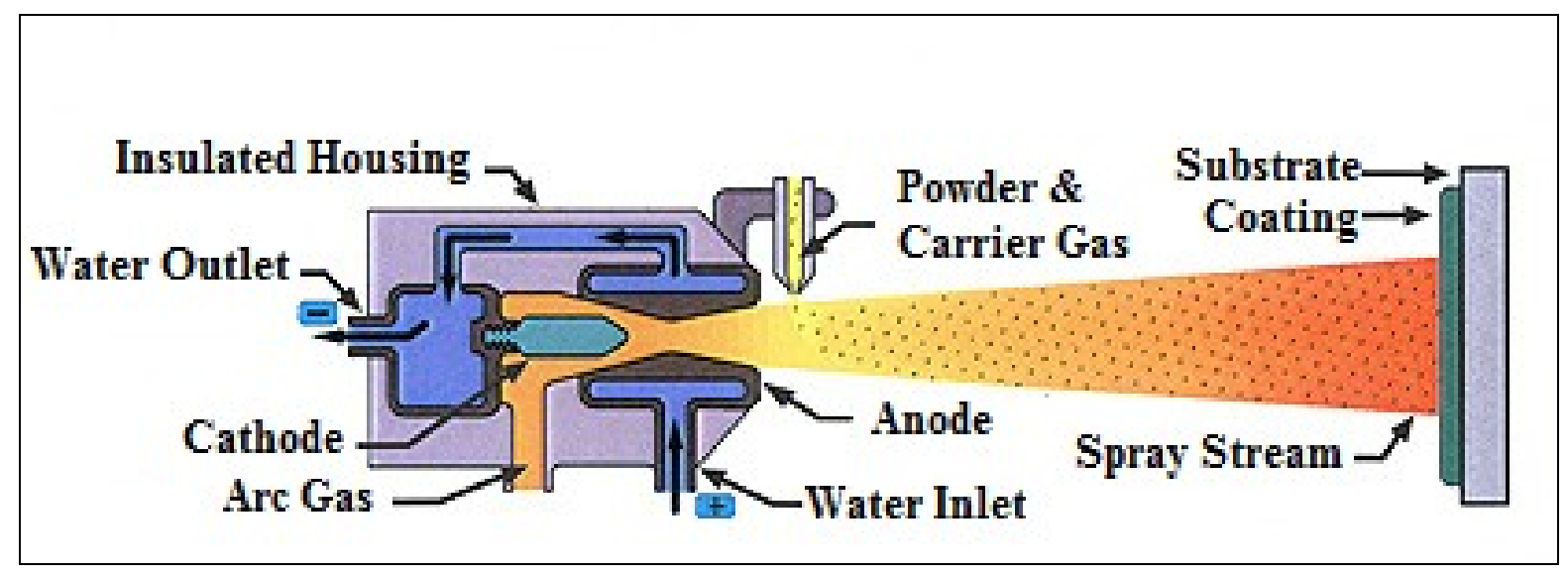

Fig. 1 - Shematic of plasma spray gun 
These studies are typically based on the statistical regression analysis, neural network, and fuzzy logic for quality control of plasma spray coating processes. De Lovelock et al. (de Villiers Lovelock et al., 1998) used the Taguchi method for optimization of process parameters of atmospheric plasma spray (APS)/high velocity oxy-fuel deposited tungsten carbide/cobalt coating. Taguchi's was unsuccessful for optimizing the spray parameters, because measured properties have too small variations to be correlated with them. The Taguchi method application was more efficient and commodious over a more extensive parameter space than that model was originally used.

Kingswell et al.(Kingswell et al., 1993) presented a model based on vacuum plasma spray deposition of metal, cermet coating using full and fractional factorial. Six parameters including chamber pressure, gun current, flow rate of plasma gases, flow rate of powder carrier gas, spray distance and their effects on particle melting and spray efficiency were considered in that model.

Processing of an alumina powder, especially injection velocity of the powder, plasma gas composition and power supplied to gun were sensitive to the variations in deposition. The nickel-based alloy metal powder and cermet materials deposition were intensive to conditions of processing. Datta et al. (Datta et al., 2013) designed an examination by using central composite design (CCD) method and analyzed the experiment with regular regression analysis. The collected data such as primary gas flow rate, stand-off distance, powder flow rate and arc current conducted as input parameters under nonlinear regression analysis and three outputs namely thickness, porosity and micro-hardness of coating obtained.

Saravanan et al. (Saravanan et al., 2001) investigated the optimization of detonation spray process parameters following a (L16-2 $\left.{ }^{4}\right)$ factorial design approach to produce high quality alumina coatings. The spray process parameters were fuel ratio, carrier gas flow rate, frequency of detonations, and spray distance. Li et al. (Li et al., 2005) studied the plasma-sprayed titanium nitride coating through third-order polynomial equations of the process parameters.

Azarmi et al. (Azarmi et al., 2008) considered the effects of APS process in presence of velocity and another components including oxide and porosity in nickel based coating. Rodriguez et al. (Rodriguez et al., 2003) designed an examination based on wear performance of $\mathrm{NiCrBSi}$ thermal spray coatings using a factor $2^{4}$. Burlacov et al. (Burlacov et al., 2006) presented a method based on dependence of photocatalytic activity of titania coating.

Parametric properties such as carrier gas flow rate, plasma power and etc. studied in that method. Wang and Coyle (Wang and Coyle, 2008) investigated the effects of six parameters on deposition efficiency and coating porosity using a designed model in plasma spray process. Artificial Neural Network (ANN) model was used in (Guessasma et al., 2003) for quality control of ceramic coating fabrication.

The proposed ANN model was built by considering the plasma and particle powder injection-processing parameters as input values and particle states as output parameter. Two models based on ANN and Fuzzy Logic (FL) were implemented in (Kanta et al., 2008) to predict the influence of power process parameters (arc current intensity, total plasma gas flow rate, and hydrogen percentage) on the inflight particle characteristics.

In this paper, an attempt is made to use the least-squares support vector machine as an interesting variant of standard support vector machines and group method of data handling network in predicting the coating properties. The advantage of the least-squares support vector machine in comparison with support vector machines is that it requires solving a set of only linear equations which is much easier and computationally simpler. The rest of the paper is organized as follows. Next section presents a description of least-squares support vector machine. Overview of the group method of data handling-type polynomial neural network technique is described in Section 3. In Section 4, the numerical results are presented and discussed. Finally, concluding remarks are given in Section 5. 


\section{Least-squares support vector machine}

The support vector machine (SVM) is a very specific type of supervised learning algorithms based on statistical learning theory and the structural risk minimization principle (Vapnik and Vapnik, 1998). The idea behind SVM is to map the input patterns into a high dimensional feature space through a suitable choice of a kernel function, and then determining the optimal hyperplane by maximizing the margins.

A major feature of SVM is that training an SVM involves the optimization of a convex cost function, which provides only global optimal, unlike neural networks training which tends to fall into a local optimal solution (Cristianini and Shawe-Taylor, 2000),(Kim, 2003).

As a modified version of original SVM, least squares SVM (LS-SVM) have been proposed by Suykens and Vandewalle by introducing a least squares error in the objective function of the optimization problem and equality instead of inequality constraints (Suykens and Vandewalle, 1999). The procedure of the LS-SVM is described as follows (Suykens et al., 2002b).

Let the training set consist of $\mathrm{N}$ datum $\left(\mathrm{x}_{1}, \mathrm{y}_{1}\right),\left(\mathrm{x}_{2}, \mathrm{y}_{2}\right), \ldots,\left(\mathrm{x}_{\mathrm{N}}, \mathrm{y}_{\mathrm{N}}\right), x \in \mathfrak{R}$ and $y \in \mathfrak{R}$. The regression model are formed with

$y=w^{T} \phi(\mathrm{x})+\mathrm{b}$

where $\phi(\cdot)$ is a nonlinear mapping function that maps $\mathrm{x}$ into the 1-dimensional space, $\mathrm{w}$ is the 1-dimensional coefficient vector and $\mathrm{b}$ is a scalar. The cost function $\mathrm{J}$ containing a penalized regression error is defined by the following equation (Abedi-Varaki and Jafari, 2017; Suykens et al., 2002b),(Suykens et al., 2002a):

$\min _{w, b, e} J(\mathrm{w}, \mathrm{e})=\frac{1}{2} w^{T} w+\frac{1}{2} \gamma \sum_{i=1}^{N} e_{i}^{2}$

Subject to

$y_{i}=w^{T} \phi\left(\mathrm{x}_{i}\right)+\mathrm{b}+\mathrm{e}_{i}, \quad i=1,2, \ldots, N$

where $\gamma$ is a positive regularization constant and $\mathrm{e}_{\mathrm{i}}$ stands for the regression error for $\mathrm{N}$ training samples. To solve this optimization problem, the restricted problem is turned into an unrestricted problem and the Lagrange function is constructed as follow (Suykens et al., 2002b),(Suykens et al., 2002a):

$L(\mathrm{w}, \mathrm{b}, \mathrm{e} ; \alpha)=J(\mathrm{w}, \mathrm{e})-\sum_{i=1}^{N} \alpha_{i}\left\{\mathrm{w}^{T} \phi\left(\mathrm{x}_{i}\right)+\mathrm{b}+\mathrm{e}_{i}-\mathrm{y}_{i}\right\}$

where $\alpha_{i}$ are Lagrange multipliers. The conditions for optimality are given by (Suykens et al., 2002b),(Suykens et al., 2002a): 


$$
\begin{aligned}
& \frac{\partial L}{\partial w}=0 \rightarrow w=\sum_{i=1}^{N} \alpha_{i} \phi\left(\mathrm{x}_{i}\right), \\
& \frac{\partial L}{\partial b}=0 \rightarrow \sum_{i=1}^{N} \alpha_{i}=0, \\
& \frac{\partial L}{\partial e_{i}}=0 \rightarrow \alpha_{i}=\gamma e_{i} \\
& \frac{\partial L}{\partial \alpha_{i}}=0 \rightarrow w^{T} \phi\left(\mathrm{x}_{i}\right)+\mathrm{b}+\mathrm{e}_{i}-y_{i}=0, i=1,2, \ldots, N
\end{aligned}
$$

By elimination of $\mathrm{w}$ and $\mathrm{e}$, the solution of the minimization problem can be obtained by solving the following linear system

$$
\left[\begin{array}{cc}
0 & 1_{N}^{T} \\
1_{N} & \Omega+\frac{1}{\gamma} I_{N}
\end{array}\right]\left[\begin{array}{l}
b \\
\alpha
\end{array}\right]=\left[\begin{array}{l}
0 \\
y
\end{array}\right]
$$

with $y=\left[\mathrm{y}_{1} ; \mathrm{y}_{2} ; \ldots ; \mathrm{y}_{N}\right], 1_{N}=[1 ; 1 ; \ldots ; 1], \alpha=\left[\alpha_{1} ; \alpha_{2} ; \ldots ; \alpha_{n}\right]$ and $\Omega_{i j}=K\left(\mathrm{x}_{i}, \mathrm{x}_{j}\right)=\phi\left(\mathrm{x}_{i}\right)^{T} \phi\left(\mathrm{x}_{j}\right)$ for $\mathrm{i}, \mathrm{j}=1,2, \ldots, \mathrm{N}$. Based on Mercer's theory, the final LS-SVM model is expressed in the following form

$$
y=\sum_{i=1}^{N} \alpha_{i} \phi\left(\mathrm{x}_{i}\right)^{T} \phi(\mathrm{x})+\mathrm{b}=\sum_{i=1}^{N} \alpha_{i} K\left(\mathrm{x}, \mathrm{x}_{i}\right)+\mathrm{b}
$$

where $\alpha$ and $\mathrm{b}$ denote the solutions to Eq. (9). There are many kernel functions, in which linear, polynomial and radial basis function (RBF) are more used.

\section{Group method of data handling (GMDH)-type polynomial neural network}

The GMDH-type polynomial neural network is organized automatically based on self-organizing learning principle. It has both characteristics of the GMDH algorithm and the conventional multilayered feed-forward neural network. The self-organizing process includes the neuron structure selection and parameter estimation. 
The parameters of each neuron are estimated separately. The neurons are evaluated, selected and engaged to the next layers which are iteratively generate and added to the network. This process continues until an optimal degree of network complexity is met (Ivakhnenko and Müller, 1995).

General connection between input and output variables can be described by a discrete form of the Volterra functional series, which is known as the Kolmogorov-Gabor polynomial and is defined in the form of the following formula:

$y=a_{0}+\sum_{i=1}^{M} a_{i} x_{i}+\sum_{i=1}^{M} \sum_{j=1}^{M} a_{i j} x_{i} x_{j}+\sum_{i=1}^{M} \sum_{j=1}^{M} \sum_{k=1}^{M} a_{i j k} x_{i} x_{j} x_{k}$

where $X\left(x_{1}, x_{2}, \ldots, x_{m}\right)$ is the input variables vector, $m$ is the number of input variables and $A\left(a_{1}, a_{2}, \ldots, a_{m}\right)$ is the vector of coefficients or weights. This full form of description can be represented by a system of partial second-order polynomials functions of two variables or neurons in the following form

$f_{k}\left(\mathrm{x}_{i}, \mathrm{x}_{j}\right)=\mathrm{a}_{0}+a_{1} x_{i}+a_{2} x_{j}+a_{3} x_{i} x_{j}+a_{4} x_{i}^{2}+a_{5} x_{j}^{2}$

The output variables $f_{k}$ are called intermediate variables. Actually, a tree of polynomials is constructed using this second-order form whose coefficients are obtained using regression technique to minimize the following prediction error

$E=\frac{\sum_{i=1}^{N}\left(\mathrm{y}_{i}-\mathrm{f}_{i}(\mathrm{x})\right)^{2}}{N} \rightarrow \min$

where $n$ is number of samples. All combinations of $m$ input variables are generated to construct the regression polynomial in the form of Eq. (12). Therefore, number of combinations in the first hidden layer of the feed-forward network from the samples $\left\{\left(y_{i}, x_{i p}, x_{i q}\right) ;(\mathrm{i}=1,2, \ldots, \mathrm{N})\right\}$ for different $p, q \in\{1,2, \ldots, \mathrm{M}\}$ is $M(M-1) / 2$. In other words it is possible to construct $N$ data triples in the following form

$$
\left[\begin{array}{lll}
x_{1 p} & x_{1 q} & y_{1} \\
x_{2 p} & x_{2 q} & y_{2} \\
x_{N p} & x_{N q} & y_{N}
\end{array}\right]
$$

Using the second-order partial description the above matrix can be rewritten in the form of following matrix

$X a=Y$ 
$a=\left[\begin{array}{llllll}a_{0} & a_{1} & a_{2} & a_{3} & a_{4} & a_{5}\end{array}\right]$
$X=\left[\begin{array}{llllll}1 & x_{1 p} & x_{1 q} & x_{1 p} x_{1 q} & x_{1 p}^{2} & x_{1 q}^{2} \\ 1 & x_{2 p} & x_{2 q} & x_{2 p} x_{1 q} & x_{2 p}^{2} & x_{2 q}^{2} \\ 1 & x_{N p} & x_{N q} & x_{N p} x_{1 q} & x_{N p}^{2} & x_{N q}^{2}\end{array}\right]$

$Y=\left[\begin{array}{lllll}y_{1} & y_{2} & y_{3} & \cdots & y_{N}\end{array}\right]^{T}$

Optimum coefficients vector are determined by solving the following formula based on multiple-regression analysis

$A=\left(A^{T} A\right)^{-1} A^{T} Y$

This operation is repeated for each neuron of the next hidden layer according to the connectivity topology of the network. However, such a solution directly from normal equations is rather susceptible to round off errors and, more importantly, to the singularity of these equations (Amanifard et al., 2008).

\section{Results and discussion}

The data related to the design parameters were collected from Ref.(Datta et al., 2013). Operational data from the plasma spraying process included four input process variables (primary gas flow rate (G), stand-off distance (D), powder flow rate (P), and arc current (A)) and three output process variables (thickness (Th), porosity (Pr), and microhardness $(\mathrm{H})$ of the coatings). The statistical parameters of the input and output data are presented in Table 1.

Table 1- Range of input-output data

\begin{tabular}{|c|c|c|c|c|}
\hline Parameter & & Minimum & Maximum & Unit \\
\hline \multirow[t]{4}{*}{ Processing parameters } & Primary gas flow rate & 7.866 & 11.8 & $10^{-4} \mathrm{~m}^{3} / \mathrm{s}$ \\
\hline & Stand-off distance & 0.15 & 0.2 & $m$ \\
\hline & Powder flow rate & 3.775 & 7.75 & $10^{-3} \mathrm{~kg} / \mathrm{s}$ \\
\hline & Arc current & 400 & 500 & $A$ \\
\hline \multirow[t]{3}{*}{ Coating properties } & Thickness & 73 & 910 & $\mu m$ \\
\hline & Porosity & 6.94 & 11.8 & $\%$ \\
\hline & Micro-hardness & 144.8 & 260.3 & $H v_{100}$ \\
\hline
\end{tabular}

Since each of the process variables had different magnitudes, scaling of data was used as the preprocessing method. Data are pre-processed (scaled to [0.1, 0.8]) through the maximum and minimum values of the variable over the whole data sets. To develop and verify the validity of the proposed model, the dataset was divided into two groups. One group included about $70 \%$ of total data was used as training samples to train the LS-SVM model, and the other included $30 \%$ 
of total data was used as test samples. Train and test sets must be different and were selected randomly from the original dataset.

In order to investigate the prediction capability of the coating properties through the models presented in this research, it is necessary to apply criteria which are capable of presenting a quantitative prediction of each model. Even though there are different statistical indexes, using a sole statistical index cannot be considered a good enough criterion for investigating the prediction accuracy of a model. The prediction accuracy of the models presented herein was studied through mean absolute error (MAE), root mean squared error (RMSE), and coefficient of determination ( $\mathrm{R}^{2}$ ) as defined bellow:

Mean absolute error (MAE):

$M A E=\frac{1}{N} \sum_{i=1}^{N}\left|y_{i}^{p}-y_{i}^{a}\right|$

Root mean square error (RMSE):

$R M S E=\sqrt{\frac{1}{N} \sum_{i=1}^{N}\left(y_{i}^{p}-y_{i}^{a}\right)^{2}}$

$R^{2}=1-\frac{\sum_{i=1}^{N}\left(y_{i}^{a}-y_{i}^{p}\right)^{2}}{\sum_{i=1}^{N}\left(y_{i}^{a}-\bar{y}^{a}\right)^{2}}$

where $N$ is the number of the training or validation samples, $y_{i}^{a}, y_{i}^{p}$ and $\bar{y}^{a}$ are the actual, predicted, and average of actual values, respectively. MAE measures the average magnitude of the errors without considering their direction. All of the individual differences are weighted equally in the average by this method. RMSE measures mean deviation of the errors. It is useful when large errors are particularly undesirable, because it gives a relatively high weight to large errors.

When the values of MAE and RMSE index are zero, the model considered will have the best possible performance. $\mathrm{R}^{2}$ presents the goodness of fit of the model and expressed as a value between zero and one. An $\mathrm{R}^{2}$ value greater than 0.9 indicates a very satisfactory model performance, while an $\mathrm{R}^{2}$ value in the range $0.8-0.9$ signifies a good performance and values less than 0.8 indicate an unsatisfactory model performance. In this work, the radial basis function (RBF) was used as the basic kernel function of LS-SVM. 
To achieve a highly accurate LS-SVM prediction, two main parameters namely regularization parameter, $\sigma^{2}$ and RBF kernel parameters, $\gamma$ have to be tuned. For this purpose, a combination of coupled simulated annealing (CSA) and a standard simplex method have been used as an efficient tuning procedure (De Brabanter et al., 2011). CSA performs the local tuning and finds good starting values of tuning parameters. These parameters are then given to simplex method to perform a fine-tuning step. The polynomial models of coating properties extracted from GMDH-type polynomial neural network are as follows:

$$
\begin{aligned}
\mathrm{X}= & 1.103-3.427(\mathrm{~A})-2.246(\mathrm{G})+7.924(\mathrm{G})(\mathrm{A})+3.526(\mathrm{~A})^{2}-1.055(\mathrm{G})^{2}-1.464(\mathrm{G})(\mathrm{A})^{2} \\
& -6.815(\mathrm{G})(\mathrm{A})^{2}-1.308(\mathrm{~A})^{3}+3.769(\mathrm{G})^{3} \\
\mathrm{Th}= & 47.408-53.535(\mathrm{X})-129.812(\mathrm{P})-282.4765(\mathrm{D})+126.643(\mathrm{P})(\mathrm{X})+12.608(\mathrm{D})(\mathrm{X})+140.872(\mathrm{D})(\mathrm{P}) \\
& +35.072(\mathrm{X})^{2}+191.729(\mathrm{P})^{2}+605.823(\mathrm{D})^{2}-28.247(\mathrm{P})(\mathrm{D})(\mathrm{X})-34.419(\mathrm{D})(\mathrm{X})^{2}-72.759(\mathrm{P})^{2}(\mathrm{X}) \\
& -37.150(\mathrm{D})(\mathrm{X})^{2}-44.550(\mathrm{D})(\mathrm{P})^{2}+44.063(\mathrm{D})^{2}(\mathrm{X})-78.823(\mathrm{D})^{2}(\mathrm{P})+0.00005079(\mathrm{X})^{3}-98.179(\mathrm{P})^{3} \\
& -382.722(\mathrm{D})^{3}
\end{aligned}
$$

$$
\begin{aligned}
\operatorname{Pr}= & 1.259-2.649(\mathrm{~A})-3.126(\mathrm{P})-0.562(\mathrm{D})-11.168(\mathrm{P})(\mathrm{A})+8.351(\mathrm{D})(\mathrm{A})+8.824(\mathrm{D})(\mathrm{P})+8.871(\mathrm{~A})^{2} \\
& +12.966(\mathrm{P})^{2}-10.661(\mathrm{D})^{2}+9.750(\mathrm{D})(\mathrm{P})(\mathrm{A})-5.105(\mathrm{P})(\mathrm{A})^{2}+6.695(\mathrm{P})^{2}(\mathrm{~A})-21.752(\mathrm{D})(\mathrm{A})^{2} \\
& +11.402(\mathrm{D})(\mathrm{P})^{2}+4.732(\mathrm{D})^{2}(\mathrm{~A})-19.911(\mathrm{D})^{2}(\mathrm{P})+3.516(\mathrm{~A})^{3}-13.041(\mathrm{P})^{3}+11.378(\mathrm{D})^{3}
\end{aligned}
$$

$$
\begin{aligned}
\mathrm{H}= & 1.418-0.766(\mathrm{~A})-9.297(\mathrm{P})+2.282(\mathrm{G})+12.838(\mathrm{P})(\mathrm{A})-11.684(\mathrm{G})(\mathrm{A})+7.865(\mathrm{G})(\mathrm{P})+2.603(\mathrm{~A})^{2} \\
& +9.282(\mathrm{P})^{2}-5.288(\mathrm{G})^{2}+2.029(\mathrm{G})(\mathrm{P})(\mathrm{A})+1.207(\mathrm{P})(\mathrm{A})^{2}-15.483(\mathrm{P})^{2}(\mathrm{~A})+0.171(\mathrm{G})(\mathrm{A})^{2} \\
& -9.023(\mathrm{G})(\mathrm{P})^{2}+10.939(\mathrm{G})^{2}(\mathrm{~A})+0.659(\mathrm{G})^{2}(\mathrm{P})-2.114(\mathrm{~A})^{3}+0.491(\mathrm{P})^{3}+2.122(\mathrm{G})^{3}
\end{aligned}
$$

where $\mathrm{X}$ is the intermediate parameter to produce polynomial model of Th. A comparison between the predictions from proposed LS-SVM and GMDH-type polynomial neural network models and the experimental values are shown for testing data set in Figs. 2 and 3. 

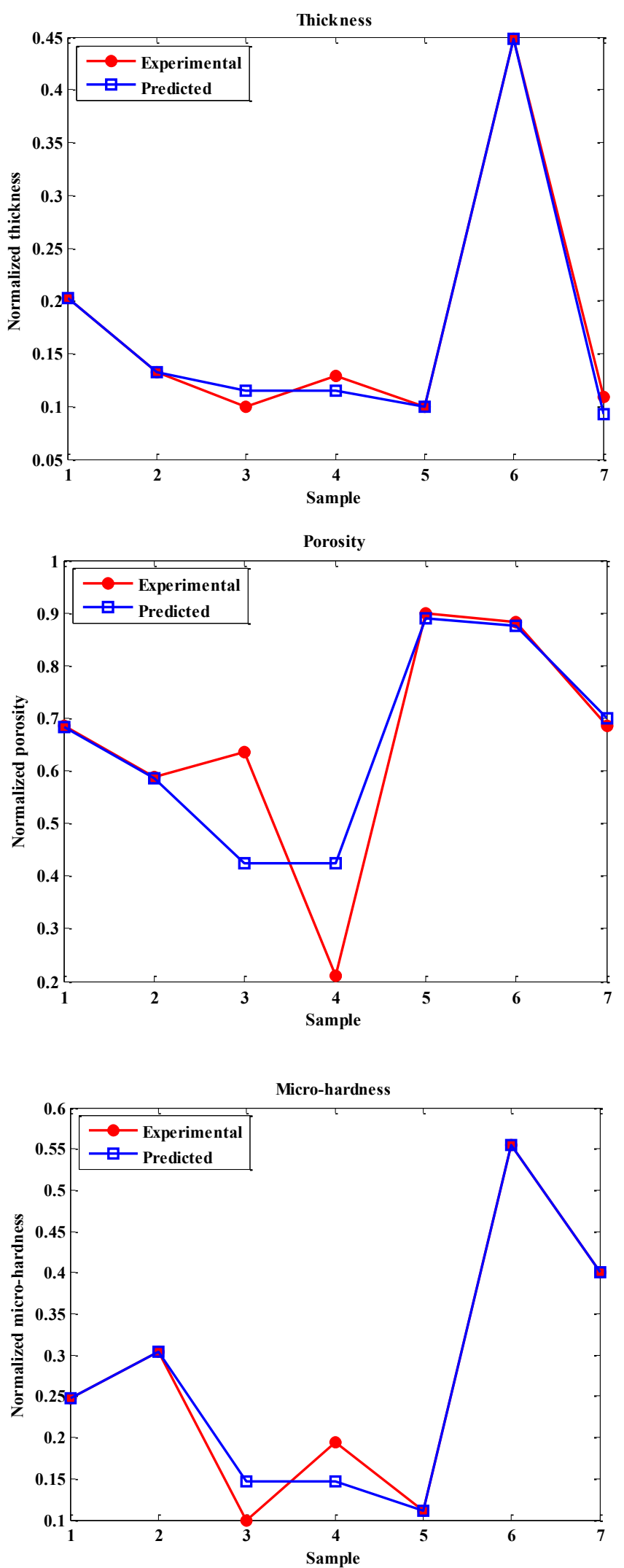

Fig. 2 - Comparison between experimental and predicted values obtained by LS-SVM model for test phase 

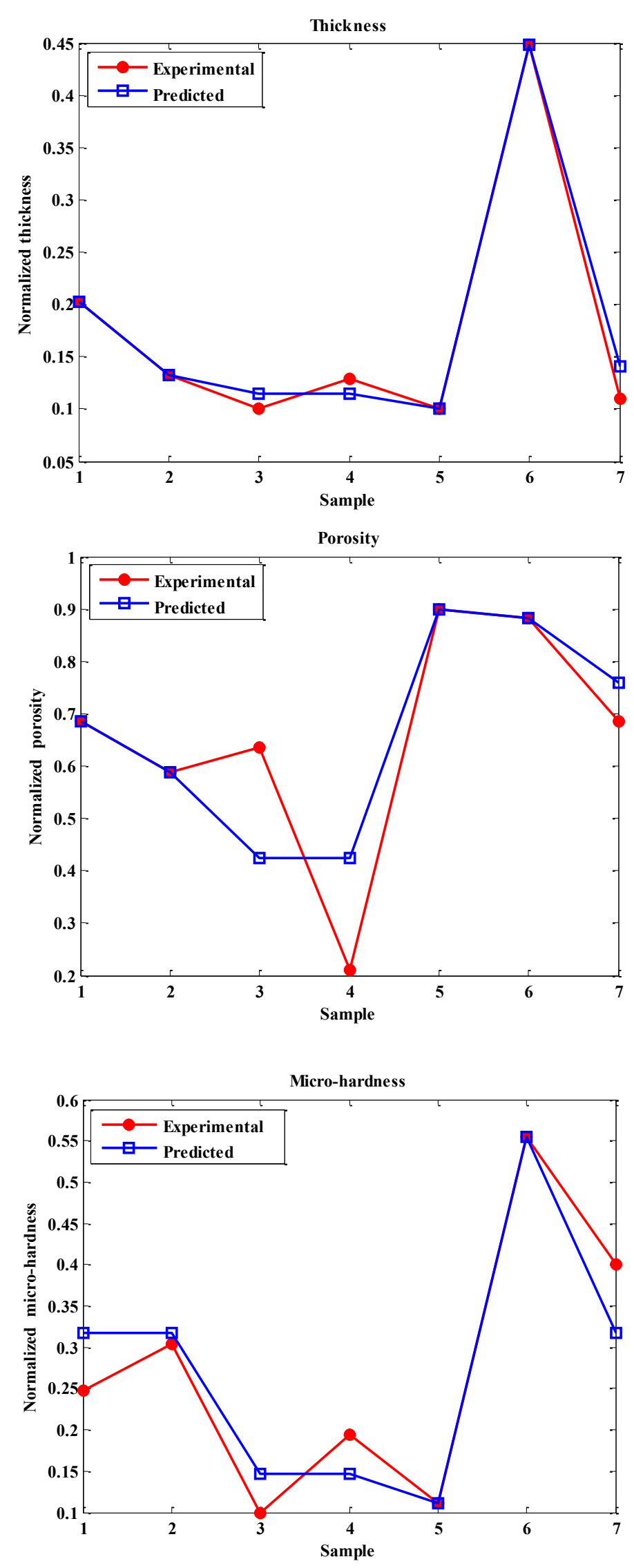

Fig. 3 - Comparison between experimental and predicted values obtained by GMDH network for test phase 
Comparing the graphs, it can be seen that both LS-SVM and GMDH-type polynomial neural network modeling results are reasonably in good agreement with the experimental results for Th. To visualize the accuracy of the presented models cross plot are depicted in Figs. 4 and 5, respectively.
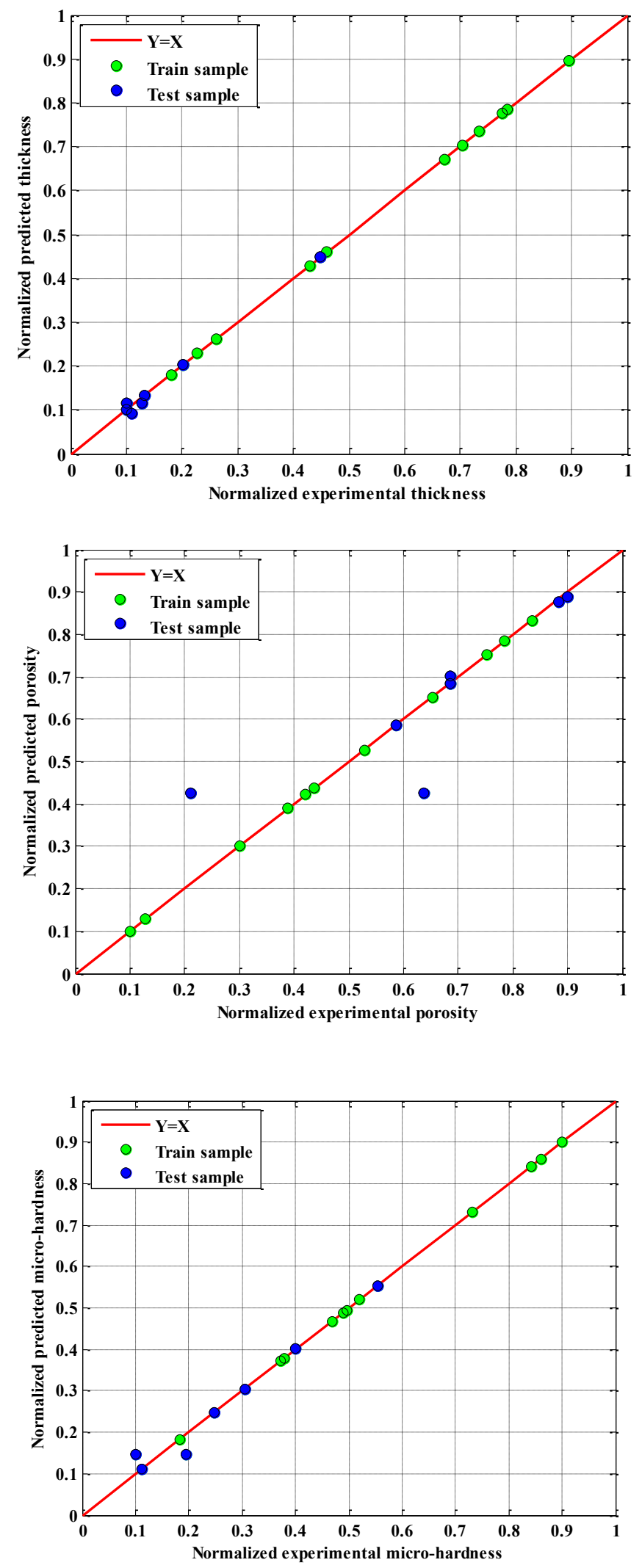

Fig. 4 - Scatter plot of experimental and predicted values obtained by LS-SVM model 

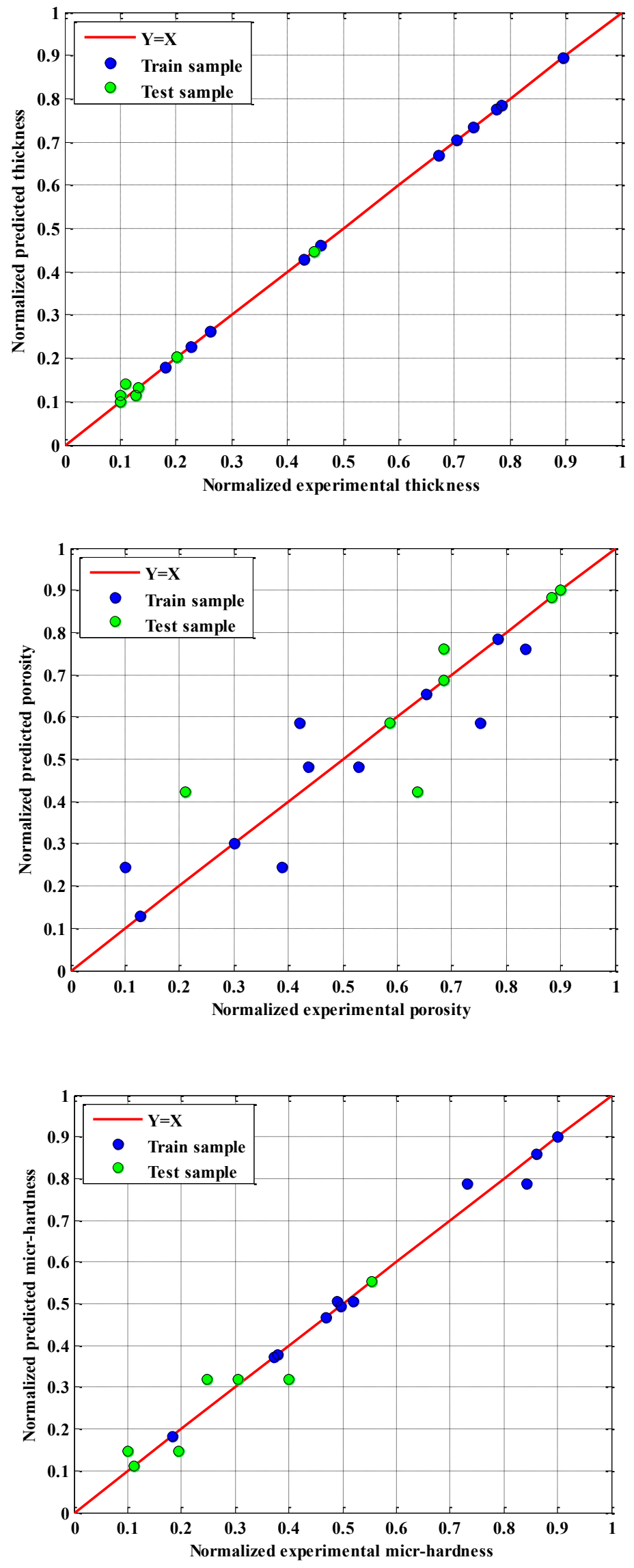

Fig. 5 - Scatter plot of experimental and predicted values obtained by GMDH network 
Cross plot shows the degree of agreement between actual data and the predicted values. In cross plot, more data points to the diagonal line signify the better performance of the model. As shown, the predictions made by the LS-SVM model yield the closest agreement with the experimental data for Th and $\mathrm{H}$. Degree of agreement between experimental data and predicted values obtained by GMDH model are in excellent, good and poor for $\mathrm{Th}, \mathrm{H}$ and $\mathrm{Pr}$ parameters, respectively.

Table 2 reports the statistical indices of the proposed LS-SVM and GMDH-type polynomial neural network. As shown in Table 2, it was obtained that both LS-SVM and GMDH-type polynomial neural network models have excellent prediction performance, where all values of MAE and RMSE are small, and all $\mathrm{R}^{2}$ are also close to unity for Th and $\mathrm{H}$ parameters.

Table 2-Statistical results

\begin{tabular}{llccc}
\hline Parameter & Model & MAE & RMSE & $\mathbf{R}^{2}$ \\
\hline Thickness & LS-SVM & 0.0066 & 0.0101 & 0.993 \\
\multirow{2}{*}{ Porosity } & GMDH & 0.0086 & 0.0141 & 0.985 \\
& LS-SVM & 0.0663 & 0.1142 & 0.712 \\
Micro-hardness & GMDH & 0.0715 & 0.1060 & 0.696 \\
& LS-SVM & 0.0136 & 0.0254 & 0.9717 \\
& GMDH & 0.0372 & 0.0484 & 0.897 \\
\hline
\end{tabular}

The results demonstrate the high capability of these models for prediction of Th and $\mathrm{H}$ values without any needs for mathematical equations of the phenomena or numerical solving of them. It can be conclude that the proposed LSSVM and GMDH-type polynomial neural network can be successfully applied to establish the forecasting models that could provide accurate and reliable prediction of thickness and micro-hardness of the coatings.

\section{Conclusion}

Considering the importance of identifying the effect of plasma spray coating processing parameters including primary gas flow rate, stand-off distance, powder flow rate and arc current on the coating properties including thickness, porosity and micro-hardness, the potential of two types of computational intelligence techniques to develop a predictive model has been studied in this paper. To this end, least-squares support vector machine and group method of data handling-type polynomial neural network were developed to model the plasma spray coating process.

The data collected from the literature was used as training and testing set. The goodness of each model was evaluated using mean absolute error, root mean square error and coefficient of determination. It can be seen from the attained results that the LS-SVM provides better prediction than the GMDH-type polynomial neural network.

For thickness and micro-hardness of coatings, both LS-SVM and GMDH-type polynomial neural network models have excellent prediction performance, where all values of MAE and RMSE are small, and all R2 are high. But for porosity of coatings, the results obtained by these models are not very well because of the high non-linearity behavior of porosity in coating process. To overcome this problem, proposed models can be trained with more training samples. 
Overall, It can be conclude that the proposed LS-SVM and GMDH-type polynomial neural network can be successfully applied to establish the forecasting models that could provide accurate and reliable prediction of coating properties.

\section{References}

ABEDI-VARAKI M, DAVTALAB M. Site selection for installing plasma incinerator reactor using the GIS in Rudsar county, Iran. Environmental monitoring and assessment.2016;188, 1-16.

ABEDI-VARAKI M, GANJOVI A, SHOJAEI F, HASSANI Z. A model based on equations of kinetics to study nitrogen dioxide behavior within a plasma discharge reactor. Journal of Environmental Health Science and Engineering.2015;13, 1 .

ABEDI-VARAKI M, JAFARI S. Self-focusing and de-focusing of intense left and right-hand polarized laser pulse in hot magnetized plasma: laser out-put power and laser spot-size. Optik-International Journal for Light and Electron Optics.2017.

AMANIFARD N, NARIMAN-ZADEH N, FARAHANI M, KHALKHALI A. Modelling of multiple short-length-scale stall cells in an axial compressor using evolved GMDH neural networks. Energy Conversion and Management.2008;49, 2588-2594.

AZARMI F, COYLE T, MOSTAGHIMI J. Optimization of atmospheric plasma spray process parameters using a design of experiment for alloy 625 coatings. Journal of Thermal Spray Technology.2008;17, 144-155.

BATHIE W, Fundamentals of gas turbines, 1996. John Wiley, New York.

BURLACOV I, JIRKOVSKÝ J, MÜLLER M, HEIMANN R. Induction plasma-sprayed photocatalytically active titania coatings and their characterisation by micro-Raman spectroscopy. Surface and Coatings Technology.2006;201, 255-264.

CLARKE D, LEVI C. Materials design for the next generation thermal barrier coatings. Annual Review of Materials Research.2003;33, 383-417.

CRISTIANINI N, SHAWE-TAYLOR J, 2000. An introduction to support vector machines and other kernel-based learning methods. Cambridge university press.

DATTA S, PRATIHAR D K, BANDYOPADHYAY P P. Modeling of plasma spray coating process using statistical regression analysis. The International Journal of Advanced Manufacturing Technology.2013;65, 967-980.

DE BRABANTER K, KARSMAKERS P, OJEDA F, ALZATE C, DE BRABANTER J, PELCKMANS K, DE MOOR B, VANDEWALLE J, SUYKENS J. LS-SVMlab toolbox user's guide. ESAT-SISTA Technical Report.2011;10.

DE VILLIERS LOVELOCK H, RICHTER P, BENSON J, YOUNG P. Parameter study of HP/HVOF deposited WCCo coatings. Journal of thermal spray technology.1998;7, 97-107.

EVANS A G, CLARKE D R, LEVI C G. The influence of oxides on the performance of advanced gas turbines. Journal of the European Ceramic Society.2008;28, 1405-1419.

EVANS A G, MUMM D R, HUTCHINSON J W, MEIER G H, PETTIT F S. Mechanisms controlling the durability of thermal barrier coatings. Progress in Materials Science.2001;46, 505-553.

GUESSASMA S, MONTAVON G, GOUGEON P, CODDET C. Designing expert system using neural computation in view of the control of plasma spray processes. Materials \& design.2003;24, 497-502.

IVAKHNENKO A, MÜLLER J-A. Self-organization of nets of active neurons. Systems Analysis Modelling Simulation.1995;20, 93-106.

KANTA A-F, MONTAVON G, VARDELlE M, PLANCHE M-P, BERNDT C C, CODDET C. Artificial neural networks vs. fuzzy logic: simple tools to predict and control complex processes - application to plasma spray processes. Journal of Thermal Spray Technology.2008;17, 365-376.

KIM K-J. Financial time series forecasting using support vector machines. Neurocomputing.2003;55, 307-319. 
KINGSWELL R, SCOTT K, WASSELL L. Optimizing the vacuum plasma spray deposition of metal, ceramic, and cermet coatings using designed experiments. Journal of Thermal Spray Technology.1993;2, 179-185.

LEVI C G. Emerging materials and processes for thermal barrier systems. Current Opinion in Solid State and Materials Science.2004;8, 77-91.

LI J, LIAO H, DING C, CODDET C. Optimizing the plasma spray process parameters of yttria stabilized zirconia coatings using a uniform design of experiments. Journal of Materials Processing Technology.2005;160, 34-42.

PADTURE N P, GELL M, JORDAN E H. Thermal barrier coatings for gas-turbine engine applications. Science.2002;296, 280-284.

PEREPEZKO J H. The hotter the engine, the better. Science.2009;326, 1068-1069.

RAIZER Y, 1987. Gas discharge physics Springer Verlag. Berlin.

RODR1GUEZ J, MART1N A, FERNÁNDEZ R, FERNÁNDEZ J. An experimental study of the wear performance of NiCrBSi thermal spray coatings. Wear.2003;255, 950-955.

SARAVANAN P, SELVARAJAN V, JOSHI S, SUNDARARAJAN G. Experimental design and performance analysis of alumina coatings deposited by a detonation spray process. Journal of Physics D: Applied Physics.2001;34, 131.

SUYKENS J A, DE BRABANTER J, LUKAS L, VANDEWALLE J. Weighted least squares support vector machines: robustness and sparse approximation. Neurocomputing.2002a;48, 85-105.

SUYKENS J A, VAN GESTEL T, DE BRABANTER J, DE MOOR B, VANDEWALLE J, SUYKENS J, VAN GESTEL T, 2002b. Least squares support vector machines. World Scientific.

SUYKENS J A, VANDEWALLE J. Least squares support vector machine classifiers. Neural processing letters.1999;9, 293-300.

VAPNIK V N, VAPNIK V, 1998. Statistical learning theory. Wiley New York.

VAßEN R, JARLIGO M O, STEINKE T, MACK D E, STÖVER D. Overview on advanced thermal barrier coatings. Surface and Coatings Technology.2010;205, 938-942.

WANG Y, COYLE T. Optimization of solution precursor plasma spray process by statistical design of experiment. Journal of Thermal Spray Technology.2008;17, 692-699. 